\title{
AVALIAÇÃO E TESTE DE EXPLICAÇÕES NA EDUCAÇÃO EM CIÊNCIAS*
}

\author{
Evaluation and testing of explanations \\ in the science education
}

\author{
Helder de Figueiredo e Paula ${ }^{1}$ \\ Antônio Tarciso Borges ${ }^{2}$
}

\begin{abstract}
Resumo: Estudantes do Ensino Fundamental atribuem aos experimentos a função avaliar a qualidade, em termos de adequação às evidências, de uma explicação ou teoria? Afinal, como os estudantes concebem o processo de avaliação de teorias ou explicações? Que função eles atribuem aos experimentos nesse contexto? Neste artigo, tratamos dessas questões com base em dados obtidos por meio de uma entrevista semi-estruturada realizada com estudantes da $7^{\mathrm{a}}$ série do Ensino Fundamental. Situamos o presente trabalho e o projeto de pesquisa no qual ele esteve inserido no contexto da busca de alternativas para a experimentação e para o avanço da compreensão da função do laboratório no ensino de ciências. Nossos dados nos permitem concluir que a concepção de experimentos para testar explicações e hipóteses é uma tarefa bastante sofisticada, mas que é plenamente possível explorar essa função no laboratório didático.
\end{abstract}

Palavras-chave: Ensino de ciências. Experimentação. Teoria e evidência. Natureza das ciências.

\begin{abstract}
How do students conceive the processes of evaluating and testing the quality of theories and explanations? Which functions do they attribute to experiments in this context? This study approaches these questions based on data obtained from semi-structured interviews with grade $7 \mathrm{stu}$ dents. Analysis of this data enabled us to evaluate how students conceive experimental tests in order to validate or reject explanations and tentative theories from their emerging understandings of this important role of experimentation. We situate the present work and the wider research project we were conducting in the context of devising alternative ways for framing and designing experimental activities leading to a better and more productive understanding of the function of science in the school laboratory.
\end{abstract}

Key words: Science education. Experiments. Theory and evidence. Nature of science.

\footnotetext{
* Com apoio parcial do CNPq.

${ }^{1}$ Doutor em Educação; Departamento de Física, Universidade Federal de Ouro Preto (DEFIS-ICEB-IFOP). Ouro Preto, MG. < helder@iceb.ufop.br>

${ }^{2}$ Doutor em Educação em Ciências; professor, Colégio Técnico e Programa de Pós-Graduação em Educação, Universidade Federal de Minas Gerais (UFMG). Belo Horizonte, MG. <tarciso@coltec.ufmg.br>
}

\footnotetext{
${ }^{1}$ Rua do Tico, 101

Caiçara - Belo Horizonte, MG

30.775-100
} 
Figueiredo e Paula, H.; Borges, A. T.

\section{Introdução}

Em um texto curto, mas provocativo, Paula (2004a) nos pergunta se o que fazemos no laboratório didático são experimentos ou experiências, e nos convida a prestar mais atenção às experiências vividas pelos estudantes durante os experimentos de laboratório. O texto chama a atenção para o papel desempenhado pelos conhecimentos prévios dos estudantes na produção de sentido e significado diante dos fenômenos (re)produzidos no laboratório de modo artificial e controlado.

Hoje, temos evidências de que o conhecimento prévio dos estudantes também é constituído por conhecimentos epistemológicos que interferem no modo como eles aprendem e interpretam os conteúdos da ciência escolar (LEACH e LEWS, 2002; DRIVER et al., 1996).

Partindo desse pressuposto, pretendemos discutir neste artigo se os estudantes: (a) atribuem, espontaneamente, aos experimentos a função de refutar uma explicação ou teoria; (b) compreendem que os experimentos também são utilizados para refutar explicações, de modo a contribuir para a sofisticação de teorias.

Bady (1979) realizou um estudo em que foi investigada a capacidade de estudantes de vários níveis escolares de compreender a função dos experimentos para o teste de hipóteses. Ele constatou, mesmo em escolas de nível superior, que os estudantes atribuem preponderantemente ao experimento a função de comprovar hipóteses e teorias. No entendimento do autor, de orientação popperiana, isso revelaria uma visão ingênua da natureza das ciências, tendo em vista o desconhecimento de que a função dos experimentos seria a de refutar e não comprovar hipóteses.

Para além das contribuições que esse tipo de investigação pode cumprir, do ponto de vista da identificação das concepções dos estudantes acerca da natureza das ciências (ver, por exemplo, PAULA, 2004b), interessa-nos aqui explorar as conseqüências didáticas do papel atribuído pelos estudantes aos experimentos no laboratório escolar.

Nossos interlocutores preferenciais não são aqueles que ainda têm uma visão tradicional e estereotipada da experimentação. Ao contrário, acreditamos que nosso trabalho pode trazer maiores contribuições àqueles que estão envolvidos na busca de alternativas para o laboratório no ensino de ciências.

Isso nos remete a uma discussão preliminar: o que seria uma visão não estereotipada da experimentação?

A função primordial dos experimentos nas ciências naturais costuma ser associada à avaliação de teorias, explicações e formas de raciocínio utilizadas para interpretar um determinado conjunto de fenômenos. Vistos sob a luz dessa função, os experimentos constituem uma das principais estratégias das ciências para produzir e validar conhecimentos.

Todavia, a exemplo do que ocorre com outras tantas questões ou problemas epistemológicos, são temas ainda em aberto a existência de um processo de avaliação racional de teorias, bem como o modo como se relacionam teorias e evidências experimentais ou observacionais.

Uma das perspectivas que nos é oferecida para o tratamento deste tema foi proposta por Popper (1972). De acordo com a teoria original de Popper, as observações e testes experimentais poderiam ser usados para selecionar, entre teorias e explicações rivais, aquelas que melhor se ajustam às evidências disponíveis, e com maior valor explicativo.

Popper (1972) compreendia o papel central desempenhado pelas teorias na realização 
de experimentos e observações. Por essa razão, para ele, o material empírico jamais poderia validar ou corroborar uma teoria. Qualquer teoria estaria sempre sujeita a ter suas previsões falseadas em testes experimentais futuros e, portanto, nunca poderia ser comprovada empiricamente. Por outro lado, as teorias cujas previsões não fossem confirmadas por um conjunto consistente e cuidadoso de experimentos e observações seriam consideradas refutadas.

O papel assimétrico desempenhado pelo material empírico oriundo de experimentos e observações controladas está na origem do termo refutacionismo, assim como das críticas de Kuhn (1979), Lakatos (1979) e Feyrabend (1977) ao que foi considerado como uma versão ingênua de refutacionismo.

Para lidar com a mesma questão, isto é, para predicar sobre o processo de validação e escolha de teorias nas ciências, Kuhn (1977) nos oferece uma perspectiva bastante diferente, que articula aspectos racionais, culturais e sociais. Uma das grandes contribuições desse autor é a formulação do conceito de valores cognitivos que definiriam critérios, apenas em parte, critérios racionais e explícitos utilizados no processo de validação das teorias. Este conceito foi retomado por Lacey (1998) que descreve o uso de valores cognitivos no seio de um conjunto de "estratégias de restrição".

A perspectiva kuhniana nega o empirismo ingênuo e o empirismo sofisticado contra os quais Popper lutou, mas também o refutacionismo que ele supunha ser uma visão mais adequada das ciências. Sob a ótica de Kuhn (1977), as teorias contaminam ou guiam a produção de evidências, tanto quanto as evidências condicionam e restringem as teorias. Em outras palavras, o fato de a natureza responder às predisposições teóricas não significa que ela se mostrará coerente com qualquer teoria.

No contexto da Educação em Ciências, Arruda, Silva e Laburú (2001) resgatam o modo como Kuhn (1979) entende a relação entre teorias e evidências, para caracterizar o laboratório didático como um espaço que permite coordenar o discurso teórico e o experimental. Em nosso ponto de vista, a principal conseqüência dessa perspectiva, para a prática pedagógica instituída na maioria de nossas escolas, é a necessidade de repensarmos o modo como os 'experimentos' escolares são propostos aos estudantes, e a relação que estabelecemos entre as aulas "práticas" e as aulas "teóricas".

Esse é um tema tratado por Borges $(2002,1997)$ que nos aponta diversas possibilidades para se coordenarem as aulas "práticas" e "teóricas". Esse autor nos fala da necessidade de planejar atividades pré e pós-laboratório, bem como defende a adoção de uma ampla gama de atividades teórico-experimentais. Além disso, Borges propõe mudanças no trabalho de laboratório, com o objetivo de deslocar o foco da atividade dos estudantes da realização de tarefas de medição e cálculos, freqüentes nos laboratórios dirigidos, para realização de interpretações sobre o significado de observações e fenômenos.

Apesar de todas as diferenças existentes entre as atividades próprias à pesquisa científica e àquelas pertinentes ao uso do laboratório na educação escolar básica, podemos afirmar que, em ambos os casos, existem seres humanos tentando construir novos entendimentos e conhecimentos acerca da sua realidade. Acreditamos que isso se dá de modo mais eficaz no contexto de resolução de problemas abertos. Em tais contextos, os atores estão enfrentando uma questão ou problema para o qual não dispõem de uma resposta conhecida que devem alcançar, ou mesmo de prescrições acerca do que devem fazer para chegar a soluções viáveis e satisfatórias. É nessa perspectiva específica que podemos admitir basicamente o mesmo 
Figueiredo e Paula, H.; Borges, A. T.

significado para a palavra experimento, seja na pesquisa científica ou na ciência escolar: o experimento é uma pergunta que fazemos à natureza (PAULA, 2004a).

Uma conseqüência importante de se conceber o experimento como uma pergunta vem do fato de que formular uma pergunta implica possuir uma expectativa inicial que deve ser negada ou confirmada mediante a obtenção da resposta. No caso das perguntas associadas a experimentos de laboratório ou observações controladas em estudos de campo, poderemos chamar nossas expectativas iniciais de hipóteses. Essas expectativas ou hipóteses desenvolvem um papel muito importante na atividade de investigação, pois dirigem toda a nossa atenção, fazendo com que observemos e consideremos determinados aspectos da realidade, enquanto ignoramos outros. São as expectativas e hipóteses que alimentamos as responsáveis por dirigir nossa seleção daquilo que é ou não relevante para nossa investigação, bem como por definir os aspectos a incluir ou excluir de nossas tentativas de modelar a situação-problema.

\section{Métodos}

Analisamos aqui uma parte dos dados obtidos por meio de uma entrevista semiestruturada, conduzida pelo primeiro autor, com nove duplas de estudantes da sétima série do Ensino Fundamental de uma escola privada, localizada em um bairro de classe média de um grande centro urbano.

A escolha da entrevista semi-estruturada como estratégia de pesquisa atende a dois objetivos não facilmente conciliáveis, que introduzem certa tensão observada na transcrição de trechos das entrevistas encontrados na próxima seção deste artigo. Por um lado, tem-se o objetivo comum às entrevistas estruturadas, em que o pesquisador direciona a entrevista para obter as informações que, de antemão, foram selecionadas como necessárias no contexto da pesquisa em desenvolvimento e adequadas aos tópicos tratados. Por outro lado, tem-se o objetivo que caracteriza entrevistas não estruturadas, em que os sujeitos têm total liberdade de abordar o tema e até transgredi-lo para abordar outros temas inicialmente não antecipados pelo pesquisador. Optamos por deixar que os entrevistados tivessem certa liberdade ao abordar as questões introduzidas pelo pesquisador sem, no entanto, deixar de reconduzir a atenção dos entrevistados para o foco principal de nosso interesse centrado em torno das questões: Como os estudantes concebem o processo de avaliação de teorias ou explicações? Que função eles atribuem aos experimentos nesse contexto?

A entrevista era composta por quatro diferentes fases, concebidas para investigar as visões dos estudantes sobre: a) as metas da ciência; b) como se conduz uma investigação científica; c) a função dos experimentos na avaliação de explicações ou teorias; d) os critérios ou bases para se admitir uma idéia, uma afirmação de conhecimento ou uma explicação como corretas e confiáveis.

Os dados aqui analisados dizem respeito ao item (c) e foram obtidos mediante um procedimento de cunho interpretativo e qualitativo. O instrumento utilizado foi pré-testado com estudantes de uma escola com características semelhantes àquela em que conduzimos a pesquisa relatada neste artigo. 
Nossa opção foi a de propor a análise de situações familiares aos estudantes. O estudo detalhado de trabalhos como os de Smith et al. (2000) nos mostrou que o uso de questões demasiadamente genéricas ou descontextualizadas não se adequava aos nossos objetivos.

Para a pesquisa realizada por Smith et al. (2000), o uso desse tipo de questão em uma entrevista não era propriamente um problema, uma vez que os autores pretendiam avaliar estudantes cuja escolarização se desenvolveu em um ambiente de aprendizagem no interior do qual reflexões de caráter epistemológico e metacognitivo foram estimuladas ao longo de muitos anos. A hipótese inicial, que foi confirmada por meio da pesquisa, era a de que esses estudantes seriam capazes de interpretar questões genéricas e remetê-las a situações específicas, de modo coerente.

No estudo que nós desenvolvemos, a prioridade era conceber situações que pudessem suscitar modos espontâneos de raciocínio e argumentação entre os estudantes. O instrumento que utilizamos consistiu na leitura e discussão de uma história que narra a realização de um experimento de laboratório por duas estudantes em uma aula de ciências (vide anexo). A leitura da história é interrompida em três momentos diferentes. A cada interrupção, o pesquisador convida os estudantes a darem suas opiniões acerca do que está sendo discutido pelas personagens.

A história foi adaptada de um extenso trabalho de pesquisa realizado por Driver et al. (1996). Em todo esse trabalho, os autores utilizaram atividades de julgamento em pequena escala, nas quais os estudantes eram reunidos em duplas ou grupos para, então, serem confrontados com questões e pequenas histórias escritas em cartões. O objetivo das atividades era estimular os estudantes a emitir opiniões e avaliações mediante a apresentação de argumentos.

Apesar de utilizar um instrumento inspirado no trabalho desses autores, nossa pesquisa é bem distinta daquela que eles conduziram. Eles pretendiam saber se: a) ocorre um desenvolvimento das imagens da ciência dos estudantes em função da idade? b) há estágios ou níveis epistemológicos que possam marcar ou caracterizar esse desenvolvimento?

Nosso trabalho não estava orientado para classificar níveis epistemológicos em função da idade, escolaridade ou outro fator qualquer. Nosso objeto de estudo, mais amplo, era caracterizar o estágio inicial de conhecimento epistemológico dos estudantes que compunham a turma na qual um projeto de pesquisa de doutorado se desenvolveu, e as conseqüências para a pratica educacional das imagens da ciência apresentadas por eles.

A história que utilizamos trata dos fenômenos da dilatação e da convecção em gases. Os estudantes que entrevistamos tinham estudado esses fenômenos ao fazerem experimentos semelhantes àquele descrito na história e realizarem discussões sobre eles em sala de aula durante o primeiro trimestre letivo do ano 2001, antes da realização das entrevistas.

Essa é uma informação importante, visto que ela justifica nossa opção em usar essa história em particular. Afinal, estávamos interessados em construir uma situação em que os estudantes raciocinassem e argumentassem com desenvoltura em um tema típico da ciência escolar. Além disso, esperávamos que os estudantes reconhecessem a fragilidade da primeira explicação oferecida por uma das personagens, o que poderia estimulá-los a avaliar a função dos experimentos para refutar explicações. 
Figueiredo e Paula, H.; Borges, A. T.

As entrevistas constituídas pelas quatro fases descritas anteriormente ocorreram em períodos de aproximadamente cinqüenta minutos e foram conduzidas com duplas de estudantes. A razão para a duração estar fixada em cinqüenta minutos deve-se ao fato de que as entrevistas foram realizadas durante o horário de aula. Em nove horários seguidos, distribuídos ao longo de três tardes, cada dupla se ausentou por um período aproximado de uma horaaula, com o consentimento dos professores das disciplinas cujas aulas estavam sendo realizadas. As entrevistas foram conduzidas na sala dos professores, que ficava situada em um local relativamente silencioso.

$\mathrm{Na}$ situação de entrevista, os estudantes encontravam-se diante, apenas, do pesquisador que eles já conheciam há duas semanas. Esse foi o período em que o pesquisador freqüentou e filmou as aulas de ciências, antes mesmo de o professor da turma iniciar o trabalho que seria alvo de análise da pesquisa (PAULA, 2004b).

O fato de a entrevista ter se realizado em duplas facilitou o processo de obtenção dos dados, reduzindo o tempo dispensado nessa tarefa. Contudo, nossa principal intenção, ao optar por esse formato de entrevista, não era a de poupar tempo. Acreditávamos que, na presença de um colega, cada aluno se sentiria mais estimulado a emitir suas próprias opiniões, argumentar a seu favor e contra-argumentar, quando confrontado com outros pontos de vista manifestados pelo companheiro. Essa expectativa é sustentada pelos resultados de pesquisas que também reúnem pares para tratar de algum tema cuja exploração é conduzida pelo pesquisador, e que são conhecidas, na literatura, como pesquisas baseadas na constituição de um grupo focal (SEVERINO, 2000). Os alunos escolheram livremente seus parceiros para a entrevista, o que contribuiu para diminuir as chances de estresse e constrangimento que a reunião de colegas sem afinidades poderia proporcionar. Aliada ao fato de já estarem familiarizados com o entrevistador, nossa escolha por trabalhar com duplas de estudantes se mostrou bastante satisfatória.

\section{Apresentação e análise dos dados}

A história utilizada como instrumento de pesquisa começa com duas personagens observando a dilatação de um balão introduzido no gargalo de uma garrafa de vidro que está cheia de ar e é submetida a um processo de aquecimento (vide anexo). Enquanto observa a dilatação, a personagem Júlia pede à personagem Sara uma explicação para o fenômeno. Analisando a resposta de Sara, notamos que o texto da história induz a associação entre os termos teoria e explicação. Nesse momento, a leitura da história é interrompida e o pesquisador pergunta aos estudantes o que a personagem Sara quis dizer ao usar a palavra teoria. Pede, também, que eles avaliem se a personagem utiliza o termo de modo correto ou se existem outros sentidos que ela poderia ou deveria atribuir à palavra teoria.

O termo teoria, nas ciências, é normalmente utilizado para designar um conjunto estruturado de afirmações que se prestam a estabelecer fatos, princípios ontológicos, leis ou regularidades, bem como modelos concebidos no esforço de compreender e descrever uma dada realidade. Esse corpo estruturado de conhecimentos conduz a investigação e a produção de novos fatos, que passam a ser aceitos, inicialmente, no interior de comunidades de pesqui- 
Avaliação e teste de explicações...

sadores para, posteriormente, fazerem parte dos bens culturais mais amplos da sociedade que sustenta e influencia o trabalho das comunidades de pesquisadores. Vê-se, portanto, que as teorias são bens culturais coletivos e têm um status epistemológico muito superior ao de uma mera "suposição pessoal ou incerta", que parece ser o sentido dado à palavra teoria pela personagem Sara.

A caracterização das personagens como estudantes e o contexto no qual a personagem Sara utiliza o termo teoria parecem ter contribuído para que a grande maioria dos estudantes entrevistados associasse o termo teoria a idéias ou suposições pessoais e incertas. Esse é um sentido atribuído à palavra teoria pelos dicionários e sua ocorrência é freqüente no diaa-dia. Apesar de ser problemático em outros contextos, principalmente quando se considera o conceito de teoria científica, tal sentido ajustou-se bem ao nosso instrumento de pesquisa.

Apresentamos, a seguir, dois trechos da conversação entre o pesquisador $(\mathrm{P})$ e duas duplas de estudantes, identificados por A1, A2, B1 e B2, logo após a segunda interrupção. A letra $\mathrm{E}$, maiúscula, seguida de um número, representa cada turno de fala ou enunciação.

\section{Diálogos entre P, A1 e A2}

durante a segunda interrupção na leitura da história

$E_{01} \Rightarrow P:$ Bom, o que vocês acham dessa explicação que a Sara deu? Dá para ter certeza de que ela está correta? A explicação é esta mesma? Tem alguma maneira de verificar se a explicação dela é boa?

$E_{02} \Rightarrow A 2:$ Não!

$E_{03} \Rightarrow$ A1: Aqui também tem que ter ar. Porque não tem jeito... Aqui continua com ar. A não ser que a garrafa fosse daquelas de papel e murchasse para o balão encher.

$E_{04} \Rightarrow P: A 2$ você concorda com $A 1$ ?

$E_{05} \Rightarrow$ A2: Concordo!

$E_{06} \Rightarrow$ P: Então, a teoria da Sara não está muito boa, não é?

$E_{07} \Rightarrow A 2: N a \tilde{o} !$

$E_{08} \Rightarrow P:$ Mas, como é que elas poderiam fazer para verificar que a teoria não está boa? Tem jeito ou não tem jeito? É só uma questão de opinião?

$E_{09} \Rightarrow A 2: E !$

$E_{10} \Rightarrow A 1:$ Não sei. Ela podia pôr a mão no balão pra ver se o ar estava quente.

$E_{11} \Rightarrow$ P: Mas, na idéia dela, o balão estaria quente sim!

$E_{12} \Rightarrow A 1:$ É, mas... então, ela põe pra controlar.

$E_{13} \Rightarrow$ P: Pois é, mas você não está concordando com a teoria dela!

$E_{14} \Rightarrow A 1:$ Não, mas......... então, quer ver, olha.........

$E_{15} \Rightarrow$ P: Então, fica sendo questão de opinião, está certo? Tipo assim, ciência seria isso: cada um com a sua opinião e não tem jeito de verificar. É isso?

$E_{16} \Rightarrow A 1$ : [fala sem muita convicção, e parece incomodado com o resultado da conversa] É... pode ser.

\section{Diálogos entre P, B1 e B2 durante a segunda interrupção} explicação?

$E_{17} \Rightarrow P:$ [referindo-se à explicação da personagem Sara] O que vocês acham dessa 
Figueiredo e Paula, H.; Borges, A. T.

$E_{18} \Rightarrow$ B1: Eu acho que a Júlia [a outra personagem] com certeza vai entender.

$E_{19} \Rightarrow P:$ Vocês acham que dá para elas terem certez̧a de que essa explicação está correta? Tem jeito de testar essa explicaşão, tipo assim: saber se ela está correta ou se não está?

$E_{20} \Rightarrow$ B2: Eu acho que tem. Você pega e far. A gente mesmo que está lendo isso aqui faz a experiência e vê se é isso mesmo.

$E_{21} \Rightarrow$ P: Mas a mesma experiência?

$E_{22} \Rightarrow B 2:$ É.

$E_{23} \Rightarrow P$ : Mas com a mesma experiência vai acontecer a mesma coisa: o balão vai inchar. A teoria da Sara é para explicar a experiência, não é? Se a gente repetir a experiência, vai acontecer, novamente, a mesma coisa. Como é que isto pode servir para testar a explicação? Para ver se ela está correta? Adianta repetir a experiência?

$E_{24} \Rightarrow$ B2: Não.

$E_{25} \Rightarrow$ P: Então, o que se poderia fazerer? Tem jeito ou não de testar a explicação?

$E_{26} \Rightarrow$ B1: Eu acho que não.

$E_{27} \Rightarrow P: E$ você B2?

$E_{28} \Rightarrow$ B2: Não!

$E_{29} \Rightarrow P:$ Para cada situação, então, a gente vai ter uma explicação. Ai é impossivel saber se uma explicaşão é boa ou ruim. Mas, então, como é que a ciência vai alcançar certeza sobre as coisas, igual vocês já falaram? Como é que o conhecimento cientifico vai ser uma coisa certa e tal, se não tem jeito de testar as idéias e explicaçôes?

$E_{30} \Rightarrow$ B1: Eu acho que eles vão pela lógica.

$E_{31} \Rightarrow$ P: E essa explicação da Sara, por exemplo, ela tem lógica?

$E_{32} \Rightarrow$ B2: Lógica eu não se ela tem não. Mas ela desperta um pouco de dúvida. Desperta dívida na pessoa.

$E_{33} \Rightarrow P:$ Desperta dúvida, mas não tem jeito de verificar se ela é certa ou errada, não é verdade? É isso?

$$
E_{34} \Rightarrow \text { B2 e B2: É! }
$$

Analisando as transcrições, vemos que a dupla constituída pelos estudantes A1 e A2 mas, principalmente, o estudante A1 - rejeita a explicação inicial elaborada por Sara. Como se poderá notar, mais tarde, A1 possui um modelo de dilatação mais sofisticado do que a personagem Sara. Por isto, percebe as limitações do modelo explicativo que ela propôs. Apesar disso, tanto A1, quanto A2 não conseguem conceber um modo de demonstrar a inferioridade ou inadequação do modelo ou da explicação que eles rejeitam. As estudantes B1e B2 também não concebem qualquer teste e nem parecem compreender as limitações do modelo de Sara com suficiente clareza, embora, em $\mathrm{E}_{32}$, a estudante $\mathrm{B} 2$ demonstre sua insatisfação com esse modelo ao afirmar que a explicação proposta pela personagem gera "um pouco de dívida na pessoa".

O entrevistador instiga as duas duplas a reconsiderar suas opiniões sobre a impossibilidade de avaliar a explicação proposta por Sara. Para isto ele propõe, em $\mathrm{E}_{15}$ e $\mathrm{E}_{29}$, a incômoda conclusão de que não há critérios com base nos quais teorias ou explicações possam ser avaliadas como sendo melhores do que outras. Diante desta provocação, ainda que de forma vaga e genérica, B2 chega a sugerir que o uso da lógica poderia servir como critério para avaliar se uma teoria é ou não correta. Contudo, essa estudante não avança no sentido de nos esclarecer sobre como a "lógica" seria usada nessas circunstâncias, e é muito provável que ela não possuísse 
a menor idéia de como isto pudesse acontecer. O estudante A1 parece aceitar a ausência de critérios ou estratégias para a avaliação de teorias, embora sua expressão facial e o tom de sua voz, ao produzir a enunciação $\mathrm{E}_{16}$, demonstrem seu desconforto diante da situação.

Mas a familiaridade dos estudantes com o fenômeno da dilatação e com teorias concebidas para interpretá-lo, bem como sua percepção da fragilidade da explicação proposta pela personagem Sara não deveriam capacitá-los a conceber testes experimentais ou a imaginar outros modos de avaliar a "teoria" proposta por essa personagem? O fato de os estudantes realizarem vários experimentos sobre dilatação em sala de aula, poucos meses antes da entrevista acontecer, não deveria facilitar a tarefa?

Como veremos no prosseguimento da entrevista, a capacidade de os estudantes conceberem experimentos ao serem estimulados a imaginar formas de testar a explicação da personagem Sara é algo completamente distinto da capacidade de contrastarem essa explicação com os resultados de experimentos concebidos por outras pessoas.

$\mathrm{Na}$ segunda parte da história contida no instrumento de pesquisa, narramos a realização de um experimento proposto pela personagem Júlia. Após a leitura desse trecho, a história foi novamente interrompida. Nessa terceira interrupção, o pesquisador perguntou aos estudantes: (i) se eles estavam surpresos com o resultado do experimento; (ii) o que esse resultado poderia dizer para as duas personagens, isto é, que evidências ele poderia trazer a favor ou contra a "teoria" apresentada inicialmente por Sara.

\section{Diálogos entre P, A1 e A2 durante a terceira interrupção}

$E_{35} \Rightarrow P: E$ aí, o que aconteceu? As duas garotas viraram e esquentaram a garrafa. Ai, o balão encheu de novo. Bom, vocês não estão surpresos com o resultado, né? [Os estudantes, através de gestos, confirmam que já esperavam o resultado] Mas, esse resultado serve para poder avaliar a teoria inicial da Sara: de que o ar quente apenas [faz uma entonação que destaca a palavra apenas, reforçandoa] sobe quando é aquecido?

$E_{36} \Rightarrow$ A1: Pode. Por aí... é.... está mostrando que não. O ar quente sobe e, aqui embaixo, como é que fica? O que vai acontecer embaixo?

$E_{37} \Rightarrow P:$ Então, o ar quente não sobe apenas, não é?

$E_{38} \Rightarrow$ A2: Ele espalha para todo lugar!

\section{Diálogos entre P, B1 e B2 durante a terceira interrupção}

$E_{39} \Rightarrow$ P: A pergunta é: o teste que a Júlia propôs.... a Júlia não explicou nada ainda, ela só propôs um teste. O teste que ela propôs dá pra avaliar a explicação da Sara? Para diz̧er que a explicação é boa ou é ruim, que tem ou não tem problemas?

$E_{40} \Rightarrow$ B2: Ela disse que o ar frio sobe, não é?

$E_{41} \Rightarrow P: O$ ar quente sobe! A Sara falou que, quando o ar esquenta, o ar quente sobe.

$E_{42} \Rightarrow$ B2: Mas e aqui? O ar frio também sobe, não é?

$E_{43} \Rightarrow P:$ Aqui onde? É aqui que você está falando? [Aponta para a ilustração usada para apresentar a explicação proposta pela personagem Sara].

$E_{44} \Rightarrow$ B2: Ham, ham [responde afirmativamente].

$E_{45} \Rightarrow$ P: Então, você está achando que o ar frio daqui está subindo? 
Figueiredo e Paula, H.; Borges, A. T.

$E_{46} \Rightarrow$ B2: $O$ ar frio também é isso aqui, não é? [Aponta novamente para as ilustrações].

$E_{47} \Rightarrow P:$ Não! Aqui é a situação da garrafa toda fria, antes de ser aquecida. Essa outra figura mostra a garrafa já quente com o balão cheio.

$E_{48} \Rightarrow$ B2: (após uns três segundos de pausa) Não, acho que os dois sobem. Acho que tem problema sim. Acho que não esclarecen qual que desce, qual que não.

Depois de obter essas respostas dos estudantes, o pesquisador terminou de ler a história. No último trecho, destacam-se: (a) o reconhecimento da primeira personagem de que o resultado do experimento desautoriza a explicação que ela havia proposto; (b) a elaboração, pela segunda personagem, de uma nova teoria coerente, tanto com o primeiro, quanto com o segundo experimento.

Ao término da história, o pesquisador apresentou perguntas finais para verificar se os estudantes reconheciam as "teorias" apresentadas pelas duas personagens como diferentes, e se eles admitiam que uma das "teorias" era superior à outra, do ponto de vista de sua adequação às evidências empíricas obtidas por meio dos experimentos. Além disso, o pesquisador retomou a opinião anteriormente apresentada pelos estudantes sobre a possibilidade de se testar uma teoria.

\section{Diálogos entre P, A1 e A2 após a apresentação das questões finais}

$E_{49} \Rightarrow P:$ Bom, aqui vão as perguntas finais. As teorias da Sara e da Júlia são diferentes?

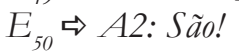

$E_{51} \Rightarrow$ A1: Sim!

$E_{52} \Rightarrow P:$ Qual delas serve melhor para explicar aquilo que aconteceu nos dois experimentos?

$E_{53} \Rightarrow A 1: O$ ar aquecido se expande!

$E_{54} \Rightarrow P:$ Mas, antes, vocês tinham falado, quando eu perguntei se na ciência havia jeito de verificar se uma teoria é melhor do que a outra, vocês falaram que não tinha jeito. E agora?

$E_{54} \Rightarrow$ A1: Tem jeito, mas... não para tudo. Algumas coisas têm jeito, sim, de se descobrir. Só... eu ia falar isso antes, que aí eles [os cientistas] podem se juntar em grupos e ai cada um tem a sua opinião, eles juntam a opinião e descobrem alguma coisa. Ah, tem jeito, mas tudo depende do que eles querem descobrir. Tem coisas que não dá não!

$E_{55} \Rightarrow P:$ Em alguns casos, não daria para verificar se uma idéia é melhor que a outra, não é?

$E_{56} \Rightarrow A 1:$ É. Em outros casos não dá.

\section{Diálogos entre P, B1 e B2 após a apresentação das questões finais}

$E_{57} \Rightarrow P$ : [Após um longo trecho não transcrito, em que a leitura da história foi repetida para que fosse possível reexplicar as diferenças entre as "teorias" das personagens Sara e Júlia] Bom, então... Estas são duas teorias diferentes, vocês não acham? Dižer que o balão enche apenas porque o ar quente sobe ou dizer que o balão enche porque o ar quente expande para todos os lados: vocês acham que são explicações diferentes?

$E_{58} \Rightarrow$ B1: Eu acho que são explicações diferentes sim, porque....[pausa] se o ar precisasse muito, muito, muito de espaço, é.... [pausa] como o ar é quente.... [pausa] ele ia acabar explodindo o balão e o vidro todo. 
$E_{59} \Rightarrow$ P: Pode ser que isso aconteça. Isso pode acontecer. Se esquentar demais, pode acontecer!

$E_{60} \Rightarrow$ B1: Aí... da outra, ela falou que o ar sobe e não precisa muito de espaço, e tal.

$E_{61} \Rightarrow P:$ Mas são diferentes as teorias?

$E_{62} \Rightarrow B 1:$ É.

$E_{63}^{62} \Rightarrow P: E$ qual delas vocês acham que está mais ajustada para esse resultado que elas obtiveram, quer dizer, vira a garrafa para cima ou para baixo, não interessa: o balão enche do mesmo jeito! Qual dessas duas idéias é mais ajustada, mais correta para explicar essa..... mais correta.

$E_{64} \Rightarrow$ B1: [interrompendo] Se a garrafa tiver de qualquer jeito, o ar vai encher o balão. É a

$E_{65} \Rightarrow$ P: Isso. Então, qual das duas: a da Sara on a da Júlia?

$E_{66} \Rightarrow$ B1: Da Júlia.

$E_{67} \Rightarrow P: A$ segunda... você acha que ela é mais coerente com as duas situações?

$E_{68} \Rightarrow$ B1: É... é essa aqui. Ela pode ficar de qualquer jeito, mas o ar vai sempre encher o balão.

$E_{69} \Rightarrow$ B2: É isso mesmo.

$E_{70} \Rightarrow P:$ Quando a gente começou a bistória, logo no começo, eu perguntei se teria jeito de testar a explicação da Sara, e ai vocês disseram que não, que não tinha jeito, né?! Disseram que era só reppetir a experiência. Mas, repetindo a mesma experiência, a explicação vai servir de novo, concordam?! Então, não dá para testar deste modo! E agora, depois da gente contar a história toda, vocês acham que tem jeito de testar uma idéia?

$E_{71} \Rightarrow$ B1: Tem!

$E_{72} \Rightarrow P:$ Quando a gente propõe uma explicação, tem jeito de ela ser testada?

$E_{73} \Rightarrow$ B1: Tem!

$E_{74} \Rightarrow P: E$ você $B 2$ ?

$E_{75} \Rightarrow$ B2: Também acho que tem sim.

Nenhum estudante, de um total de 18 sujeitos entrevistados, chegou a conceber um teste experimental para avaliar a explicação ou a "teoria" proposta pela personagem Sara, nem mesmo mediante a insistência do entrevistador. Nenhum deles, tampouco, avançou no sentido de propor critérios com base nos quais uma explicação ou teoria poderia ser julgada.

Conceber testes experimentais para avaliar teorias ou explicações requer que o estudante seja capaz de imaginar a aplicação da "teoria" ou do modelo a situações específicas de modo a antever suas implicações. Uma vez extraídas as implicações, elas podem ser utilizadas para simular os fenômenos na mente, processo que produz previsões susceptíveis de verificação experimental. Por um lado, esse exercício demanda conhecimento e o desenvolvimento da prática de modelamento por meio de atividades explicitamente voltadas para este propósito.

Os autores da história realizaram essas operações e se fizeram representar por intermédio da personagem Júlia. Na história, Júlia ficou incomodada com a imagem concebida pela personagem Sara, que atribuiu ao ar aquecido um movimento exclusivamente ascendente. Júlia, então, simulou o fenômeno em sua mente e concluiu que, caso essa idéia estivesse correta e a garrafa fosse virada de ponta a cabeça, o balão não poderia parecer inflado. Esta previsão, gerada por simulação mental, com base na aceitação, por hipótese, do modelo concebido por Sara, sugeriu a Júlia um experimento. Interpretamos a concepção desse experimento como o resultado de um processo de modelamento, em que os autores da história produzem um modelo do fenômeno e o utilizam para fazer previsões. 
Figueiredo e Paula, H.; Borges, A. T.

Esta descrição do processo de concepção do experimento atribuído à personagem Júlia demonstra que a capacidade de conceber testes empíricos para uma teoria ou explicação é uma tarefa bastante complexa e envolve processos de modelamento.

Entretanto, nós observamos que a dificuldade dos estudantes para conceber, por si mesmos, um teste para avaliar o modelo de Sara não os impediu de reconhecer que o resultado do teste proposto por Julia contradizia as idéias que sustentavam esse modelo. A análise dos diálogos ocorridos entre o pesquisador e a dupla $\mathrm{A} 1$ e $\mathrm{A} 2$, no trecho que vai de $\mathrm{E}_{21}$ a $\mathrm{E}_{26}$, indica isso.

Há que se notar, a este respeito, que a dupla A1 e A2, desde o início: (a) havia identificado problemas na explicação proposta pela personagem Sara; (b) apresentou sinais de que possuía uma compreensão do processo de dilatação semelhante àquele construído posteriormente pela personagem Júlia. Lembramos que a turma já tinha estudado Física Térmica, embora não conhecesse especificamente o experimento descrito na história. Em função disso, não é surpreendente que A1 e A2 não tenham sido perturbados pelos resultados do segundo experimento.

Não temos clareza acerca de como as estudantes B1 e B2 entendiam o fenômeno da dilatação antes de serem expostas à história. Mas, aparentemente, elas não possuíam idéias claras a este respeito. O que notamos é a grande dificuldade que essas duas estudantes manifestam em compreender as explicações que as personagens apresentaram ao longo da história. $\mathrm{O}$ trecho que vai de $\mathrm{E}_{57}$ a $\mathrm{E}_{69}$ representa apenas um fragmento do esforço despendido pelo pesquisador e pelas estudantes para que as idéias contidas nas explicações veiculadas pela história se tornassem mais claras para elas.

Apesar de toda essa dificuldade de compreensão, vemos que as estudantes conseguem, finalmente, reconhecer os pontos fracos da "teoria" construída pela personagem Sara, e o resultado do teste experimental como uma contra-evidência em relação à "teoria" que havia sido proposta por essa personagem.

Nos trechos $\mathrm{E}_{44}$ a $\mathrm{E}_{47}$ ou $\mathrm{E}_{70}$ a $\mathrm{E}_{75}$, vemos que as duas duplas reavaliam sua posição inicial e passaram a admitir, abertamente, a possibilidade de que teorias ou explicações científicas sejam sujeitas a testes experimentais ou outras estratégias de avaliação racional. O estudante A1, entretanto, mantém a convicção de que isso nem sempre é possível ${ }^{3}$. Em $\mathrm{E}_{54}, \mathrm{~A} 1$ afirma que há casos em que a avaliação de teorias é possível, mas há casos que não. O estudante vincula a avaliação de teorias na ciência à busca de um consenso entre os cientistas. Assim, ele revela sua convicção de que a produção do conhecimento científico é uma atividade social e um empreendimento coletivo.

\footnotetext{
${ }^{3}$ Embora o diálogo com o pesquisador não tenha avançado no sentido de se discutir quais as situações em que testes experimentais são ou não possíveis, sabemos que nem todo o conhecimento científico está sujeito a testes ou se enquadra na perspectiva falsificacionista, que, segundo Popper (1972), permitiria distinguir afirmações científicas e não científicas.
} 
Avaliação e teste de explicações...

\section{Considerações finais}

No início deste artigo, perguntamos se os estudantes atribuem, espontaneamente, aos experimentos, a função de refutar uma explicação ou teoria, ou se compreendem que os experimentos são utilizados para testar hipóteses, de modo a contribuir para a sofisticação de teorias. Em função dos dados e discussões apresentados anteriormente, podemos afirmar que a concepção de experimentos para testar explicações e hipóteses é uma tarefa bastante sofisticada. Os resultados que apresentamos aqui sugerem que é plenamente possível explorar essa função no laboratório didático, mesmo no Ensino Fundamental.

A impressão que tivemos, ao final da seção da entrevista descrita neste artigo, foi a de que os estudantes não atribuíam um significado bem definido ao que nós chamamos, no corpo do artigo, de "teste de uma explicação". Isso explica o estranhamento apresentado por eles a uma das perguntas formuladas no protocolo da entrevista semi-estruturada, e que pode ser encontrada em $\mathrm{E}_{01}$ ou em $\mathrm{E}_{19}$, quando o pesquisador lhes pergunta se há alguma forma de testar a explicação fornecida pela personagem Sara para saber se essa explicação estava ou não correta. Todavia, a produção de um sentido para o "teste de uma explicação" parece ter ocorrido durante a entrevista, por intermédio da leitura do resto da narrativa reproduzida no anexo. Isso nos leva a duas breves conclusões. Em primeiro lugar, significa que a própria entrevista se transformou em uma experiência de aprendizagem, haja vista a capacidade da grande maioria dos estudantes de compreender a função desempenhada pelo "teste" apresentado pela personagem Júlia no decorrer da história. Em segundo lugar, a aparente incapacidade dos estudantes para atribuir um significado à expressão "teste de uma explicação" pode ser interpretada como um sinal de que a experiência escolar dos estudantes entrevistados não havia estado orientada pelas diretrizes curriculares que iremos caracterizar brevemente em nossas considerações finais. Tais diretrizes apontam para a necessidade de se apresentarem as ciências como uma atividade de investigação e produção de hipóteses ou conjeturas necessariamente submetidas à verificação.

Atividades desenvolvidas com a finalidade de se testar empiricamente idéias e explicações são raramente encontradas nas escolas de educação básica e, mesmo, de nível superior. Mais comumente o laboratório escolar é orientado para ilustrar fenômenos específicos que mostram se o comportamento de objetos e sistemas está em concordância com o que foi previsto por uma determinada lei ou teoria. O laboratório ganha uma dimensão de instância de demonstração, quando não de comprovação e verificação, que tem conseqüências sérias na formação geral dos estudantes, em desacordo com várias diretrizes curriculares para a educação em ciências recentes (AAAS,1989; BRASIL, 1998).

A meta de promover o desenvolvimento de imagens mais sofisticadas sobre o processo de produção e validação do conhecimento científico vem sendo proposta desde a primeira metade do século XX, sendo hoje amplamente compartilhada por educadores, cientistas e formuladores de currículos (AKERSON, ABD-EL-KHALICK e LEDERMAN, 2000). Entretanto, a realização desse velho objetivo não tem sido alcançada, e a grande maioria dos alunos e dos professores de ciências naturais apresenta concepções ingênuas sobre a atividade e o conhecimento científicos.

Como aponta Borges $(2002,1997)$, existem diversos objetivos pedagógicos associados à experimentação no ensino de ciências. $\mathrm{O}$ educador deve estar atento às diferentes fun- 
ções do laboratório e procurar balancear o currículo de forma a contemplar, por um lado, atividades de modelamento e construção de novos conhecimentos, e, por outro, atividades de enriquecimento das experiências e fenômenos conhecidos pelos estudantes. Deve ser próprio da atividade de ensinar ciências: permitir que os estudantes aprendam as teorias e modelos mais importantes da ciência, mas, ao mesmo tempo, propiciar oportunidades para o desenvolvimento de recursos cognitivos que lhes permitam compreender e avaliar novas idéias, ou para compreender a natureza provisória do conhecimento cientifico.

Pode-se questionar se é viável que os estudantes aprendam a testar hipóteses e avaliar explicações na educação escolar básica. Para lidar com essa questão, de início, temos de estabelecer que os estudantes não são pequenos cientistas. Eles não dispõem do mesmo envolvimento afetivo com as questões e problemas propostos pela ciência escolar que os cientistas exibem em relação às questões que constituem o foco de suas pesquisas. Tampouco os estudantes dominam as mesmas estratégias de raciocínio e recursos que os cientistas usam para conceber experimentos, reunir evidências e coordená-las com as teorias e modelos disponíveis. Entre esses recursos, podemos citar: o conhecimento específico do assunto; o hábito de ler continuamente as produções de outros cientistas sobre os seus campos de interesses; o hábito de submeter à avaliação e crítica de seus pares, oralmente ou por escrito, os resultados de seus estudos; o domínio de táticas de investigação, e técnicas associadas ao uso de equipamentos. Por outro lado, as interações sociais que influenciam as decisões dos cientistas e os significados que eles atribuem às evidências obtidas por meio dos experimentos são completamente diferentes daqueles que podemos encontrar em comunidades de aprendizagem na educação escolar. É marcante - no caso dos estudantes - a pressão para cumprir tarefas escolares e a expectativa de atender às exigências do programa e do professor.

Contudo, é preciso dizer que não existem apenas diferenças, mas também semelhanças entre o que se faz no contexto da pesquisa e algumas das experiências vividas no laboratório didático, por estudantes que lidam com a resolução de problemas abertos e autênticos, como os descritos por Jimenez-Aleixandre (1998) ou Borges (2002).

Assim, por exemplo, a história que utilizamos como instrumento de pesquisa pode ocorrer em sala de aula. Nesse caso, é provável que o papel representado pela personagem Júlia tenha de ser desempenhado pelo professor, embora estudantes afetivamente mais envolvidos com o tema em estudo e mais habilidosos em extrair conseqüências empíricas de idéias ou explicações também possam sugerir experimentos ou testes experimentais.

Nosso estudo sugere que os estudantes não utilizam, necessariamente, de modo espontâneo, e mesmo quando estimulados, estratégias para a avaliação de teorias. Esse é o tipo de conhecimento importante a ser desenvolvido pela educação em ciências, e é preciso incluí-lo no planejamento escolar e considerá-lo como meta curricular importante a ser perseguida. A questão "como sabemos o que sabemos e por que acreditamos no que acreditamos?" deve ser colocada de modo mais freqüente, e o confronto entre hipóteses e explicações com evidências empíricas e testes experimentais deve fazer parte das estratégias de ensino e aprendizagem.

Por meio das interações com os objetos de conhecimento e os experimentos, em conjunto com o professor e os estudantes mais habilidosos ou mais envolvidos afetivamente com o tema, pode-se promover o desenvolvimento do pensamento-em-ação de todos os estudantes que se dispuserem a se envolver efetivamente no processo. Trata-se, portanto, da constituição de um ambiente de aprendizagem, no interior do qual a educação em ciências é estru- 
Avaliação e teste de explicações...

turada com base em atividades de investigação. Nesse ambiente, o aprender a "fazer ciências" não fica limitado ao controle de variáveis ou à adoção de "cuidados metodológicos", tais como o rigor no tratamento de dados ou o uso de estratégias para a atenuação de erros de medida, embora estes sejam aspectos importantes a serem ensinados, como defendem Borges e Gomes (2005).

A construção coletiva de problemas, o levantamento de conhecimentos prévios, de expectativas e hipóteses, a realização de investigações e a avaliação das evidências disponíveis constituem, nesse ambiente, um novo modo de integrar o aprender ciências, o aprender a fazer ciências e o aprender sobre ciências (PAULA, 2004a; MILLAR, 1996; HODSON, 1993). Esse ambiente utópico constitui uma referência, também utópica, para repensarmos novos papéis para a experimentação no ensino de ciências. Ao perseguir essa utopia, pretendemos avançar nossas práticas, procurando promover uma educação em ciências que contribua verdadeiramente para a construção da autonomia moral e intelectual de nossos estudantes.

\section{Referências}

AAAS. American Association for the Advancement of Science. Project 2061: science for all americans. New York: Oxford University Press, 1989.

AKERSON, V. L.; ABD-EL-KHALICK, F.; LEDERMAN, N. G. Influence of a reflective Explicit Activity-Based Approach on Elementary Teachers' Conceptions of Nature of Science. Journal of Research in Science Teaching, New York: John Wiley \& Sons, v. 37, n. 4, p. 295-317, 2000.

ARRUDA, S. M.; SILVA, M. R.; LABURÚ, C. E. Laboratório didático de física a partir de uma perspectiva kuhniana. Investigações em Ensino de Ciências, Porto Alegre, v. 6, n.1, 2001. Disponível em: < http://www.if.ufrgs.br/public/ensino/revista.htm>. Último acesso em: jul. 2007.

BADY, R. J. Student's understanding of the logic of hypothesis testing. Journal of Research Science Teaching, New York, v. 16, n. 1, p. 61-65, 1979.

BORGES, A. T. Novos rumos para o laboratório escolar de ciências. Caderno Brasileiro de Ensino de Física, Florianópolis, v. 19, n. 3, p. 291-313, 2002.

. O papel do laboratório no Ensino de Física. In: ENCONTRO NACIONAL DE PESQUISA EM EDUCAÇÃO EM CIÊNCIAS, 1., 1997, Águas de Lindóia, SP. Atas... Águas de Lindóia, 1997. p. 2-11.

; GOMES, A. D. T. Percepção de estudantes sobre o desenho de testes

experimentais. Caderno Brasileiro de Ensino de Física, Florianópolis, v. 22, n. 1, p. $77-$ 95, 2005.

BRASIL. Ministério da Educação e Cultura. Diretrizes curriculares nacionais para o Ensino Médio brasileiro. Brasília: MEC, 1998. 
Figueiredo e Paula, H.; Borges, A. T.

DRIVER, R. et al. Young people's images of science. Buckingham: Open University Press, 1996.

FEYRABEND, P. K. Contra o método. Rio de janeiro: Livraria Francisco Alves, 1977.

HODSON, D. Re-thinking old ways: towards a more critical approach to practical work in School Science. Studies in Science Education, Leeds, v. 22, p. 85-142, 1993.

JIMENEZ-ALEIXANDRE, M. P. Diseño curricular: indagación y racionamiento com el lenguaje de las Ciências. Enseñanza de las Ciências, Barcelona, v. 16, n. 2, p. 203-216, 1998.

KUHN, T. S. Lógica da descoberta ou psicologia da pesquisa? In: LAKATOS, I.; MUSGRAVE, A. (Orgs.). A crítica e o desenvolvimento do conhecimento. São Paulo: Cultrix/Editora da Universidade de São Paulo, 1979. p. 5-32.

. A tensão essencial. Lisboa: Edições 70, 1977.

LACEY, H. Valores e atividade científica. São Paulo: Discurso Editorial, 1998.

LAKATOS, I. O falseamento e a metodologia dos programas de pesquisa científica. In: LAKATOS, I.; MUSGRAVE, A. (Orgs.). A crítica e o desenvolvimento do conhecimento. São Paulo: Cultrix/Editora da Universidade de São Paulo, 1979. p. 109-243.

LEACH, J.; LEWS, J. The role of student's epistemological knowledge in the process of conceptual change in Science. In: LIMON, M.; MASON, L. (Eds.). Reconsidering conceptual change: issues in theory and practice. Dordrecht: Netherlands, Kluwer Academic Publishers, 2002. p. 201-216.

MILLAR, R. Towards a science curriculum for public understanding. School Science Review, Hatfield, UK, v. 77, p. 7-18, 1996.

PAULA, H. F. Dicionário crítico da educação: experimentos e experiências. Presença Pedagógica, Belo Horizonte, v. 10, n. 60, p. 74-76, 2004 a.

- A ciência escolar como instrumento para a compreensão da atividade científica. 2004. 363f. Tese (Doutorado) - Faculdade de Educação, Universidade Federal de Minas Gerais, Belo Horizonte, 2004b.

POPPER, K. A lógica da pesquisa científica. São Paulo: Cultrix, 1972.

SEVERINO, A. J. Metodologia do trabalho científico. 21. ed. São Paulo: Cortez, 2000.

SMITH, C. L. et al. Sixth-Grade students' epistemologies of Science: the impact of school science experiences on epistemological development. Cognition and Instruction, Mahwah, NJ, v. 18, n. 3, p. 349-422, 2000.

Artigo recebido em agosto de 2006 e aceito em janeiro de 2007.

190

Ciência Æ̊̉ Educação, v. 13, n. 2, p. 175-192, 2007 


\section{Anexo: A história do balão cheio de ar aquecido}

Julia e Sara estavam fazendo uma atividade durante uma aula de ciências. $\mathrm{Na}$ atividade, um balão de borracha foi preso no gargalo de uma garrafa (veja a figura). A professora, que se chamava Maria Auxiliadora, disse para as garotas aquecerem o vidro da garrafa e, então, observar o que iria acontecer. Ao seguiram essas instruções, Julia e Sara notaram que o balão tornava-se maior.

- O balão está crescendo, disse Julia. Por que será que isto está ocorrendo?

- É o ar, respondeu Sara, quando o ar fica quente, mais ar entra dentro do balão. Olhe, você pode ver o ar enchendo o balão. Existe mais ar dentro dele agora.

- Sim, disse Julia, mas por que será que isto acontece?

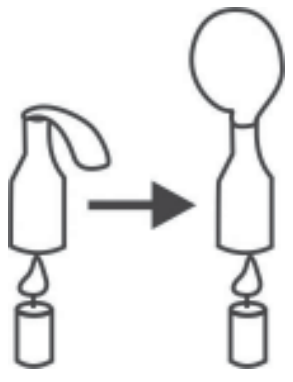

. Bem, eu tenho uma teoria para explicar isso..., respondeu Sara.

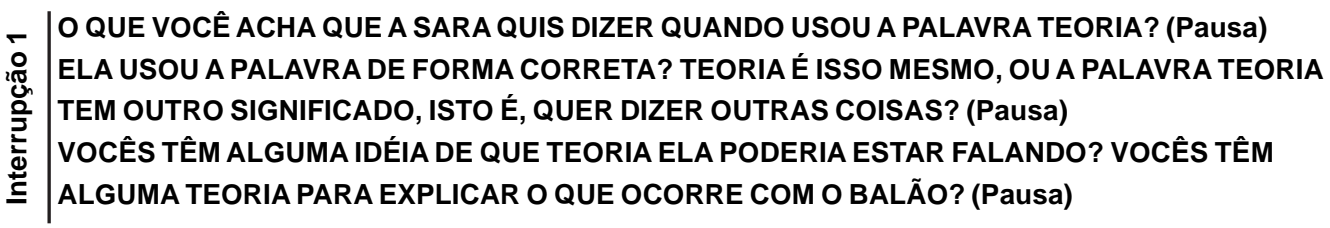

. Conte-me então, disse Julia, que teoria você tem?

- Bem, disse Sara. Eu acho que isto acontece porque o ar quente sobe. Você sabe que nós podemos sentir o ar quente subindo quando ligamos aquecedores e coisas assim. Eu acho que, quando nós aquecemos a garrafa, aquecemos também o ar dentro dela que, então, se torna quente e sobe. Ao subir, o ar enche o balão.

Neste momento, Sara fez um desenho para explicar a Julia o que ela estava querendo dizer (veja a figura).
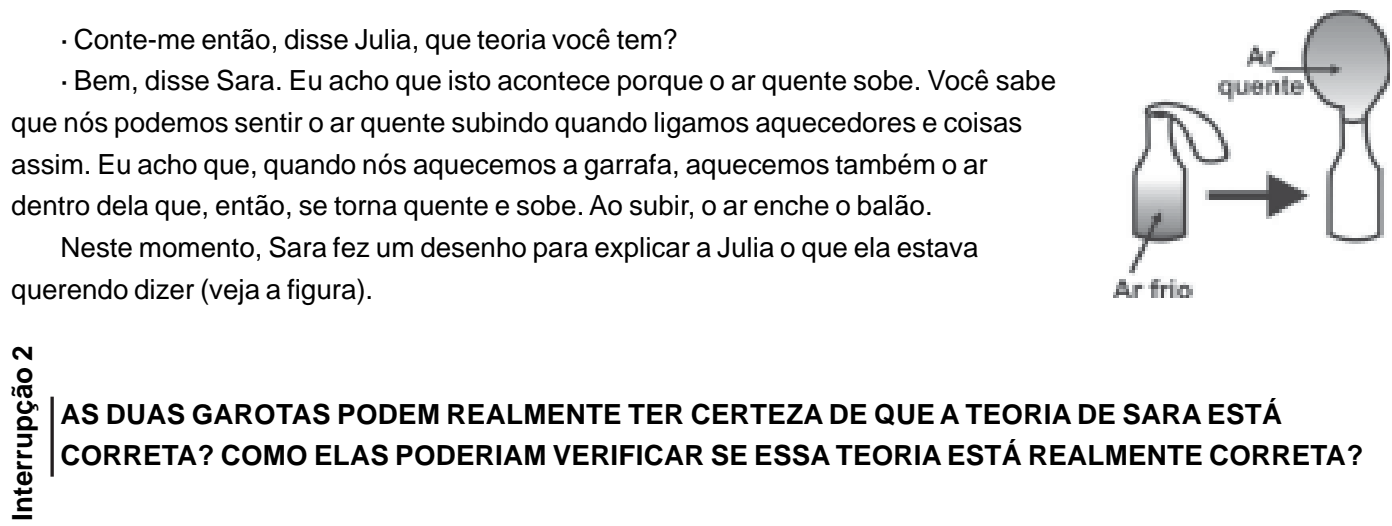

Julia pensou sobre a explicação de Sara por um minuto.

Eu acho que eu não concordo totalmente com sua explicação, ela disse. Se sua idéia está correta, o que aconteceria se nós aquecêssemos a garrafa mantendo-a virada de cabeça para baixo? Se o ar quente sobe, ele iria para a cima e se acumularia no fundo da

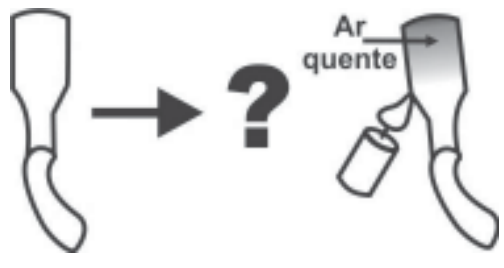
garrafa sem encher o balão, não é? (veja a figura).

- Legal Julia, deixe-me verificar sua idéia. Eu vou virar a garrafa fria com o balão ainda murcho. Vou colocar tudo de cabeça para baixo. Aí eu vou aquecer a garrafa e ver o que acontece. (veja o resultado da experiência na figura)

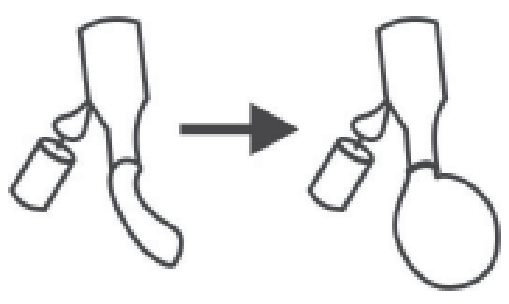


Figueiredo e Paula, H.; Borges, A. T.

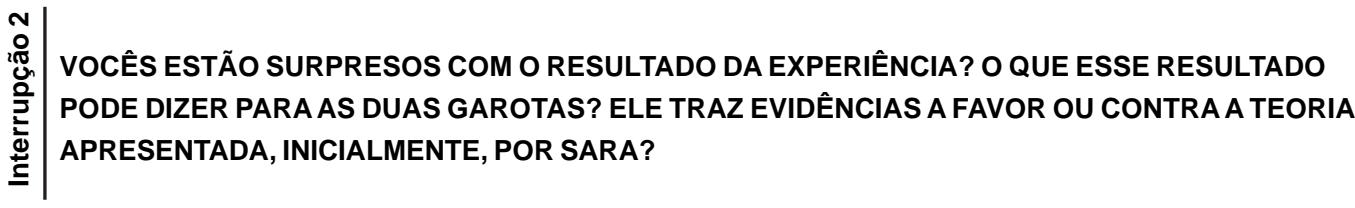

Eu não pensava que isto pudesse acontecer, disse Sara. Eu não sabia que deste jeito o balão também poderia ficar maior.

As duas garotas pensaram por um minuto. Então, Julia disse:

- Minha teoria é a de que o ar se expande quando é aquecido. Então, ele precisa de mais espaço, e é isto que faz com que o balão fique maior.

Sara, então, disse:

- O que a palavra expandir significa?

- Significa ficar maior e precisar de mais espaço, explicou Julia.

AS GAROTAS TÊM, AGORA, DUAS DIFERENTES TEORIAS PARA EXPLICAR POR QUE O BALÃO TORNA-SE MAIOR QUANDO A GARRAFA É AQUECIDA: $1^{\circ}$ - AR QUENTE SOBE; $2^{\circ}$ - AR AQUECIDO SE EXPANDE. VOCÊ ACHA QUE ESSAS TEORIAS SÃO DIFERENTES?

QUAL DAS DUAS VOCÊS ACHAM MELHOR PARA EXPLICAR AQUILO QUE PODE SER OBSERVADO NA EXPERIÊNCIA?

CONSIDERANDO O FINAL DA HISTÓRIA, VOCÊS GOSTARIAM DE REVER A OPINIÃO QUE VOCÊS HAVIAM APRESENTADO, ANTERIORMENTE, SOBRE A POSSIBILIDADE DE SE TESTAR UMA TEORIA, AUMENTANDO NOSSA AVALIAÇÃO DE QUE ESSA TEORIA É REALMENTE CORRETA? 